\title{
Atividade antitumoral do Ageratum conyzoides L. (Asteraceae)
}

\author{
Luciano da Silva Momesso, ${ }^{1}$ Rute Mendonça Xavier de Moura, ${ }^{2}$ Dulce Helena Jardim \\ Constantino $^{*}, 2$
}

\author{
${ }^{1}$ Faculdades Integradas de Ourinhos, Rod. BR 153, km 338,4, Bairro Água do Cateto, 19909-100 Ourinhos-SP, \\ Brasil \\ ${ }^{2}$ Centro de Ciências Biológicas e da Saúde, Universidade do Sagrado Coração, Rua Irmã Arminda, 10-50, \\ Jd. Brasil, 17011-160 Bauru-SP, Brasil
}

\begin{abstract}
RESUMO: O Ageratum conyzoides, vegetal conhecido popularmente no Brasil é constituído por várias substâncias químicas, dentre elas os flavonóides, aos quais já foi atribuída a atividade antitumoral. Neste estudo foi avaliado o efeito das frações clorofórmica e metanólica do extrato AcOEt das folhas sobre o crescimento do tumor de Ehrlich. Foi constatado que o tratamento com as frações metanólicas, nas doses de $50 \mathrm{mg} / \mathrm{kg}$ de peso foi eficaz, inibindo o crescimento tumoral. A porcentagem de inibição para a fração metanólica estabilizada foi de 69,84\% e de 68,25\% para a fração metanólica não estabilizada. Estudos posteriores se fazem necessários para esclarecer quais os mecanismos envolvidos nesta inibição do crescimento tumoral.
\end{abstract}

Unitermos: Ageratum conyzoides, Asteraceae, atividade antitumoral, tumor de Ehrlich.

\begin{abstract}
Antitumoral activity of the Ageratum conyzoides L. (Asteraceae)". Ageratum conyzoides, a popular vegetal in Brazil, is composed by many chemical compounds, including flavonoids, and antitumoral activity has been attributed to it. In this assay the effect of chloroform and methanol fractions from EtOAc extract of the leaves on the growth of the Ehrlich tumor was evaluated. Under our experimental conditions we have observed that the treatment with methanol fractions, under the dosage of $50 \mathrm{mg} / \mathrm{kg}$ was efficient on inhibiting the tumoral growth. There was an inhibition percentage of $69.84 \%$ to the stabilized methanol fraction and $68.25 \%$ to the nonstabilized fraction. Further studies are necessary to clarify which mechanisms are involved in the inhibition of the tumoral growth.
\end{abstract}

Keywords: Ageratum conyzoides, Asteraceae, antitumoral activity, Ehrlich tumor.

\section{INTRODUÇÃO}

O Ageratum conyzoides é uma planta nativa da América, com adaptação a diversas condições ambientais, estabelecendo-se em várias regiões de clima tropical e subtropical do mundo. Varia desde o sudeste da América do Norte até a América Central. Também é encontrado em vários países de regiões tropicais e subtropicais, inclusive no Brasil. Planta considerada invasora em cerca de cinquenta países, em outros tem valor como ornamental, na Malásia é usada como forrageira para cabras, bovinos e muares (Castro et al., 2006; Ming, 1999; Ladeira et. al., 1987), que floresce entre setembro e outubro. É uma planta silvestre, ruderal, habitando desde terrenos úmidos a secos e elevados, nas margens de estradas e culturas (SiqueiraJaccoud, 1961).

Acomposição principal do A. conyzoides ébaseada em óleos essenciais com terpenos (salineno, pineno, eugenol, cineol, felandreno, limoneno, linalol, terpineol e cariofileno), compostos cumarínicos e benzofuranos, resinas, alcalóides, flavonas, flavonóides e cromonas
(Laus, 1994). Suas formas de extrato mais utilizadas são a infusão a $2 \%$ e a $5 \%$, tintura a $20 \%$ e extrato glicoalcoólico. Ocorrem também a presença de cromenos, principalmente os precocenos I e II, que causam metamorfose prematura em diversas espécies de insetos, levando à formação de adultos estéreis (Castro et al., 2004; Castro et al., 2006).

A planta exerce elevada gama de atividade biológica, tais como atividade antimicrobiana, na cicatrização de feridas de queimaduras, no tratamento de cólicas, diarréia, flatulência e reumatismo agudo, ação vasoconstritora, analgésica e antinflamatória (Barbosa etal., 1994; Durodola, 1977; Ladeira et al., 1987). Sua atividade antiinflamatória foi confirmada cientificamente por trabalho financiado pela extinta Central de Medicamentos (CEME). Recentemente foi relatado que a decocção de suas folhas demonstraram atividade frente a inflamações ovarianas, amenorréia, dismenorréia, reumatismo e diarréia (Agra et al., 2008). Contém também alcalóides pirrolizidínicos, presentes nos ramos floríferos, os quais apresentam elevada hepatoxicidade (Castro et al., 2006).

A atividade antitumoral foi relatada em estudo 
realizado por Ravishankar et al. (1994), efeito atribuído provavelmente aos flavonóides presentes no vegetal. Embora alguns trabalhos tenham mostrado que os flavonóides podem apresentar efeito mutagênico, em geral são considerados como benéficos no tratamento de doenças circulatórias e hipertensão, agindo como cofator da vitamina C (Zuanazzi \& Montanha, 2000). Outras atividades biológicas também são conferidas aos flavonóides, sendo a principal delas a atividade antioxidante, além de antiproliferativa e moduladora da transdução de sinais celulares (Muschietti \& Martino, 2007).

Em vista dos fatos relatados anteriormente, este estudo teve como principal objetivo a avaliação do efeito antitumoral do Ageratum conyzoides (frações clorofórmica e metanólica do extrato bruto) utilizando-se como modelo experimental o tumor ascítico de Ehrlich em camundongos.

\section{MATERIAIS E MÉTODOS}

\section{Material vegetal}

A planta foi cultivada no Horto de Plantas Medicinais e Aromáticas da Coordenadoria de Assistência Técnica Integral (CATI) de Bauru-SP e suas folhas foram coletadas em 18 de setembro de 2000 . Um exemplar de $A$. conyzoides é mantido no Herbário Baur da Universidade do Sagrado Coração de Bauru-SP. Uma parte do material vegetal obtido foi submetido ao processo de estabilização por autoclavagem $\left(121{ }^{\circ} \mathrm{C}, 15 \mathrm{~min}\right)$ a fim de inativar possíveis interferentes no extrato a ser obtido. Estas frações estabilizadas receberam a sigla E (estabilizado) e as não estabilizadas, a sigla NE.

\section{Preparo das frações}

Folhas do vegetal foram previamente secas em estufa de ar circulante e então pulverizadas. Em seguida os pós foram ressuspensos em acetato de etila e particionados com uma solução metanol-água (9:1), sendo obtidas as frações AcOEt-E e AcoEt-NE, as quais foram concentradas. As frações hidroalcoólicas foram particionadas com clorofórmio, sendo obtidas as frações $\mathrm{MeOH}-\mathrm{E}, \mathrm{MeOH}-\mathrm{NE}$, CL-E e CL-NE. Todas as frações foram suspensas em $0,2 \mathrm{~mL}$ de água destilada estéril, com auxílio de um aparelho de ultra-som e banho-maria e filtradas em algodão com a finalidade de se obter doses de 50 e $100 \mathrm{mg} / \mathrm{kg}$ de peso.

\section{Animais}

Foram utilizados camundongos suíços, machos, de quatorze semanas, com $25 \mathrm{~g}$ em média. Durante a fase experimental os animais receberam ração balanceada e água ad-libitum.

\section{Neoplasia}

Foi empregado o Tumor Ascítico de Ehrlich (TAE). Foi implantada uma suspensão contendo $10^{6}$ células neoplásicas, em $0,1 \mathrm{~mL}$ de solução salina apirogênica, por via intraperitoneal (IP). Avaliação do crescimento tumoral foi realizada através de contagem de células tumorais presentes no lavado peritoneal, dez dias após o implante. A determinação do número total de células neoplásicas foi realizada através da contagem das suspensões coradas por cristal violeta a $0,5 \%$ em Câmara de Neubauer.

\section{Tratamento}

Grupos com dez animais cada foram tratados com frações CL-E, CL-NE, MeOH-E e MeOH-NE nas doses de 50 e $100 \mathrm{mg} / \mathrm{kg}$ de peso através de injeção i.p. O grupocontrole recebeu injeção de solução salina esterilizada.

\section{Análise estatística}

O estudo dos resultados obtidos foi realizado por análise de variância não-paramétrica, utilizando o teste de Kruskal-Wallis, complementado com as comparações múltiplas entre porções de tratamento (Siegel \& CastellanJr, 1988).

\section{RESULTADOS E DISCUSSÃO}

Comparando-se o grupo-controle e aqueles tratados com as frações clorofórmicas estabilizada (CL-E) e não estabilizada (CL-NE) de 50 e $100 \mathrm{mg} / \mathrm{kg}$ é possível observar indução do crescimento neoplásico, onde não houve interferência do processo de estabilização. Não são observadas diferenças significativas entre os grupos, porém é possível inferir que com as doses de $100 \mathrm{mg} / \mathrm{kg}$ a indução do crescimento neoplásico foi menor. Os dados estão dispostos na Tabela 1 .

Tabela 1: Avaliação do crescimento tumoral nos grupos tratados pelas frações clorofórmicas.

\begin{tabular}{|c|c|}
\hline GRUPOS & $\begin{array}{c}\text { TAE } \\
\text { (contagem) }\end{array}$ \\
\hline Fração clorofórmica não estabilizada 100 mg/kg & $85,00 * \pm 47,50 * *$ \\
\hline Fração clorofórmica não estabilizada 50 mg/kg & $89,50 * \pm 47,50 * *$ \\
\hline Fração clorofórmica estabilizada 100 mg/kg & $92,00 * \pm 92,50 * *$ \\
\hline Fração clorofórmica estabilizada 50 mg/kg & $100,00 * \pm 97,00 * *$ \\
\hline \multirow[t]{2}{*}{ Solução salina estéril a 0,9\% } & $63,00 * \pm 36,50 * *$ \\
\hline & $\mathrm{p}<0,01 * * *$ \\
\hline \multicolumn{2}{|l|}{$\begin{array}{l}\text { * valores expressos em mediana } \\
* * \text { semi-amplitude total } \\
* * * \text { nível de significância }(\mathrm{p}<0,01)\end{array}$} \\
\hline & $\begin{array}{r}\text { Rev. Bras. Farmacogn. } \\
\text { Braz. J. Pharmacogn. } \\
\text { 19(3): Jul./Set. } 2009\end{array}$ \\
\hline
\end{tabular}


A Figura 1 representa o efeito das frações clorofórmicas (FR-CL) estabilizada e não estabilizada sobre o crescimento neoplásico nas doses de 50 e $100 \mathrm{mg} /$ $\mathrm{mL}$.

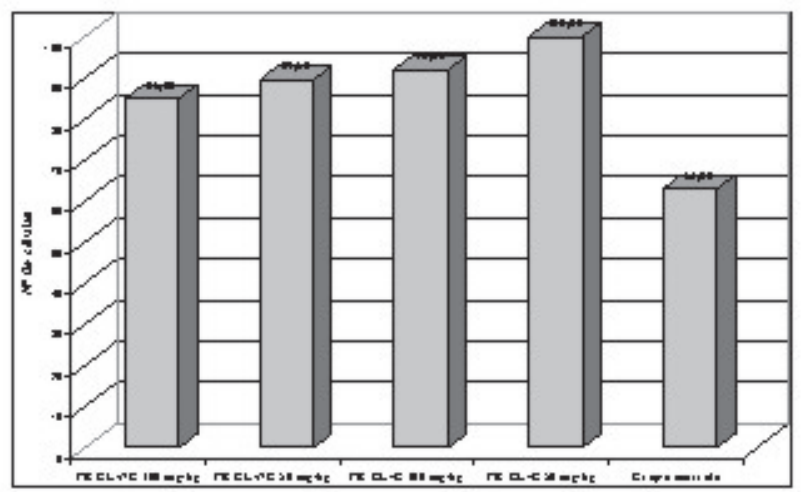

Figura 1. Efeito das frações clorofórmicas no crescimento do Tumor Ascítico de Ehrlich.

Ocorreu indução do crescimento tumoral nos grupos tratados com as frações clorofórmicas e isto sugere atividade sinérgica dos compostos químicos ou a existência de substâncias indutoras. Ming (1999) relata a presença de precocenos em plantas, que são substâncias com potencial indutor de mitoses, sendo, portanto, estimulantes da divisão celular, fato observado no desenvolvimento de larvas de alguns insetos. Craveiro \& Machado (1986) relatam que muitas plantas produzem micromoléculas tais como alcalóides, flavonóides, triterpenos, limonóides, dentre outras, que apresentam indução mitótica e com isso função de proteção contra fitopatógenos e insetos fitófagos.

Com relação aos resultados obtidos dos tratamentos com as frações metanólicas, exceto o grupo tratado com a fração metanólica não estabilizada $(\mathrm{MeOH}-$ $\mathrm{NE}$ ) de $100 \mathrm{mg} / \mathrm{kg}$, todos apresentaram crescimento tumoral inferior ao grupo-controle, sem diferença significativa em comparação a este último. Os grupos tratados com as frações metanólicas não estabilizada (MeOH-NE) de 50 $\mathrm{mg} / \mathrm{kg}$ e estabilizada (MeOH-E) de $50 \mathrm{mg} / \mathrm{kg}$ apresentaram menor crescimento tumoral, com diferenças de valores não significativas estatisticamente. $\mathrm{O}$ tratamento com a fração $\mathrm{MeOH}-\mathrm{E} 100 \mathrm{mg} / \mathrm{kg}$ reduz o crescimento neoplásico de forma significativa. Este resultado foi superior aos apresentados pelos grupos tratados com as frações $\mathrm{MeOH}-$ $\mathrm{NE} 50 \mathrm{mg} / \mathrm{kg}$ e Me-OH-E $50 \mathrm{mg} / \mathrm{kg}$, sendo esta variação estatisticamente significativa.

A dose utilizada na fração MeOH-NE $100 \mathrm{mg} /$ $\mathrm{kg}$ não é ideal para o tratamento, podendo-se sugerir então que o efeito do tratamento com as frações $\mathrm{MeOH}$ é dosedependente.

Os resultados obtidos são sugestivos de que o potencial observado em relação às frações $\mathrm{MeOH}$ de A. conyzoides são eficazes no tratamento do tumor de Ehrlich. Porém, há necessidade de purificação das frações para a realização de novos experimentos e observação de possíveis atividades relacionadas a sinergia da mistura de substâncias nas frações ou se o efeito está no potencial das substâncias puras.

$\mathrm{Na}$ Tabela 2 encontram-se os resultados do crescimento tumoral obtidos nos grupos de tratamento com as frações metanólicas e do grupo-controle.

Tabela 2. Avaliação do crescimento tumoral nos grupos tratados pelas frações metanólicas.

\begin{tabular}{lc}
\hline \multicolumn{1}{c}{ GRUPOS } & $\begin{array}{c}\text { TAE } \\
\text { (contagem) }\end{array}$ \\
\hline Fração metanólica não estabilizada $100 \mathrm{mg} / \mathrm{kg}$ & $67,50^{*} \pm 36,00^{* *}$ \\
Fração metanólica não estabilizada $50 \mathrm{mg} / \mathrm{kg}$ & $20,00^{*} \pm 15,50^{* *}$ \\
Fração metanólica estabilizada $100 \mathrm{mg} / \mathrm{kg}$ & $37,00^{*} \pm 70,00^{* *}$ \\
Fração metanólica estabilizada $50 \mathrm{mg} / \mathrm{kg}$ & $19,00^{*} \pm 59,50^{* *}$ \\
Solução salina estéril a $0,9 \%$ & $63,00^{*} \pm 36,50^{* *}$ \\
\hline
\end{tabular}

* valores expressos em mediana

** semi-amplitude total

*** nível de significância $(\mathrm{p}<0,01)$

Na Figura 2 estão representados os dados obtidos para o tratamento dos animais com as frações metanólicas ( $\mathrm{MeOH}) \mathrm{de} A$. conyzoides.

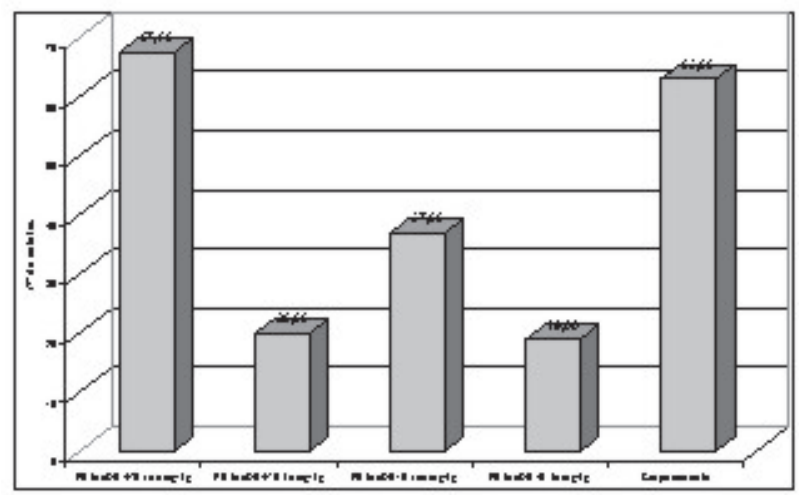

Figura 2. Efeito das frações metanólicas no tratamento do Tumor Ascítico de Ehrlich.

A Figura 3 revela os resultados da atividade inibitória dos extratos. As frações metanólicas $\mathrm{MeOH}$ $\mathrm{NE} 50 \mathrm{mg} / \mathrm{kg}$ e MeOH-E $50 \mathrm{mg} / \mathrm{kg}$ são as que ilustraram resultados mais significativos.

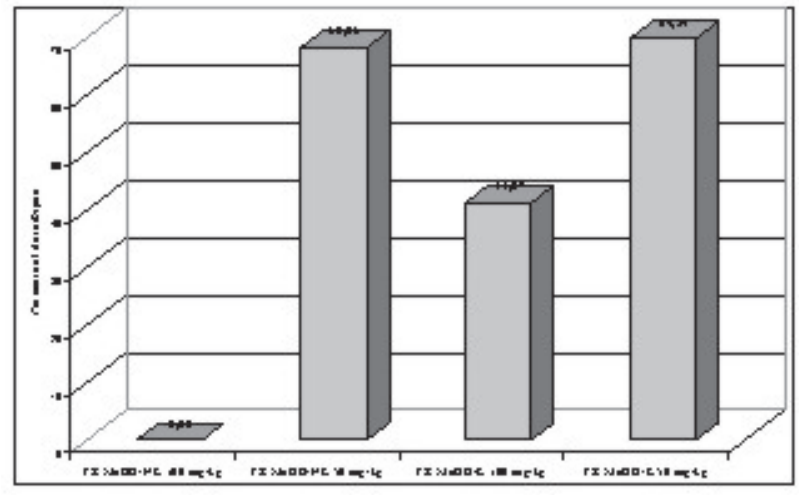


Figura 3. Inibição percentual do crescimento tumoral para os grupos tratados com as frações metanólicas.

A estabilização é um processo que utiliza o calor e a pressão como princípios básicos para a inativação de agentes deletérios nas plantas, como por exemplo enzimas que catalisam processos bioquímicos e alteram as substâncias presentes nos vegetais. Pode-se sugerir que estas diferenças observadas entre as frações estabilizadas e não estabilizadas são devidas a atividade da temperatura aliada a pressão, que podem ter alterado os constituintes químicos presentes nas frações (Prista et al., 1992). Falkenberg et al. (2000) relatam que podem ocorrer alterações estruturais dos compostos químicos presentes no extrato vegetal, o que levaria a uma variação significativa entre as frações submetidas a esse processo quando comparadas àquelas que não passaram por esse procedimento.

A sinergia de substâncias pode ocorrer com freqüência, podendo tornar a fração mais ou menos ativa, podendo também contribuir com a toxicidade. Os resultados obtidos sugerem uma provável ocorrência de sinergia entre compostos químicos nas frações.

Como os objetivos deste trabalho foram apenas avaliar o efeito das frações obtidas do extrato bruto de $A$. conyzoides, são necessários estudos complementares para a elucidação das dúvidas surgidas aqui.

\section{AGRADECIMENTOS}

Os autores agradecem à Universidade do Sagrado Coração de Bauru-SP e aos professores Dr. Jairo Kenupp Bastos e Dr. Fernando Batista da Costa do Laboratório de Farmacognosia e Princípios Ativos Naturais da FCFRPUSP.

\section{REFERÊNCIAS BIBLIOGRÁFICAS}

Agra MF, Silva KN, Basília IJLD, Freitas PF, Barbosa-Filho JM 2008. Survey of medicinal plants used in the region Northeast of Brazil. Rev Bras Farmacogn 18: 472-508.

Barbosa AD, Ferreira RCV, Valente PHM 1994. Atividade antimicrobiana de extratos fluidos de plantas medicinais brasileiras. Lecta 12: 153-163.

Castro HG, Oliveria LO, Barbosa, LCA, Ferreira FA, Silva, DJH, Mosquim PR, Nascimento EA 2004. Teor e composição do óleo essencial de cinco acessos de mentrasto. Quim. Nova 27: 55-57.

Castro HG, Ferreira FA, Silva, DJH, Ribeiro-Jr JI 2006. Análise do crescimento de acessos de mentrasto (Ageratum conyzoides L.) em dois ambientes. Rev Ciência Agronôm 37: 44-49.

Craveiro AA, Machado DI 1986. De aromas, insetos e plantas. Ciência Hoje 4: 54-63.

Durodola JI 1977. Antibacterial property of crude extracts from herbal wound healing remedy - Ageratum conyzoides. Planta Med 32: 388-390.

Ladeira AM, Zaidan LBP, Figueiredo-Ribeiro RCL 1987. Ageratum conyzoides L. (Compositae): germinação, floração e ocorrência de derivados fenólicos em diferentes estádios de desenvolvimento. Hoehnea 15: 53-62.

Laus CB 1994. Manual de fitoterapia: plante saúde. Curitiba: Prefeitura Municipal de Curitiba.

Ming LC 1999. Ageratum conyzoides: a tropical source of medicinal and agricultural products. In: Janick J (ed.) Perspectives on new crops and new uses. ASHS Press. p. 469-473.

Muschietti LV, Martino VS 2007. Atividades biológicas dos flavonóides naturais. In: Yunes RA, Cechinel-Filho V. Química de produtos naturais, novos fármacos e a moderna farmacognosia. Itajaí: Univali. p. 183-208.

Prista LN, Alves AC, Morgado RM 1992. Técnica farmacêutica e farmácia galênica. Lisboa: Fundação Calouste Gulbenkian.

Ravishankar T, Vedavalli L, Nambi AA, Selvam V 1994. Role of tribal people in the conservation and utilisations of plant genetic resources. Madras: MSSRF.

Siegel S, Castelann-Jr NJ 1988. Nonparametric statistics for the behavioral sciences. New York: McGraw-Hill.

Falkenberg MB, Santos RI, Simões CMO. Introdução à Análise Fitoquímica. In: Simões CMO, Schenkel EP, Gosmann G, Mello JCP, Mentz LA, Petrovick PR (orgs.) 2000. Farmacognosia da planta ao medicamento. Porto Alegre/ Florianópolis: UFRGS/ UFSC.

Siqueira-Jaccoud RJ 1961. Contribuição para o estudo farmacognóstico do Ageratum conyzoides L. Rev Bras Farmácia 42: 177-197.

Zuanazzi JAZ, Montanha JA 2000. Flavonóides. In: Simões CMO, Schenkel EP, Gosmann G, Mello JCP, Mentz LA, Petrovick PR (Org.). Farmacognosia da planta ao medicamento. Porto Alegre/Florianópolis: UFRGS/UFSC, 489-516. 